This is a post-print version of the following article: Casas, Helena; Rovira-Esteva, Sara. 2009. «Orientalism and Occidentalism: two forces behind the image of the Chinese language and construction of the modern standard». Journal of Multicultural Discourses, 4(2):107-121.

\title{
Orientalism and Occidentalism: two forces behind the image of the Chinese language and construction of the modern standard
}

\author{
Helena Casas-Tost and Sara Rovira-Esteva* \\ Universitat Autònoma de Barcelona
}

\begin{abstract}
This article identifies the principal myths and misconceptions surrounding the Chinese language and, by means of discourse analysis, shows how they have been expressed and become entrenched in the academic world, both in China and in the West, despite the evidence which undermines the premises on which these myths are founded. We also show how these views originated from applying a Western linguistic model to descriptions and reforms of the Chinese language, thus reinforcing the orientalist discourse on Chinese that still persists and has permeated the Chinese language teaching. We tackle these issues from a Spanish perspective at a time when the country is experiencing important educational changes at three levels. First, there is an increase in courses on Chinese Studies. Second, European university curricula are undergoing a process of homogenisation. And, third, a new policy to standardise language learning, teaching and assessment at all stages of education is being implemented all over Europe. We are concerned about this policy because the model designed for European languages is also being applied to non-European languages. We believe that this new context is an ideal occasion to question existing discourses and bring forth new approaches towards the production and reproduction of knowledge related to the Chinese language.
\end{abstract}

Keywords: Chinese language; orientalism; Western views of the Chinese language; knowledge production and reproduction; westernisation; East Asian Studies

\section{Introduction}

\footnotetext{
*Corresponding author. Email: Sara.Rovira@uab.cat
} 
The importance of Edward Said's Orientalism: Western Conceptions of the Orient (1979) lies not only in highlighting how the Western world has used academic discourse as yet another instrument for colonialism and ideological manipulation in the Orient, but also how the Orient itself has adopted this discourse to its own ends. Despite the controversial nature of this book and the fact that it does not explicitly focus on East Asia, it is particularly thought-provoking and serves as an appropriate starting point for a critical reading of the academic discourse on various aspects of the Chinese language discussed in this article, not only as far as how this discourse has been generated, but also how these views have been accepted and constantly reproduced with little or no questioning, as Said $(1979,116)$ denounced:

Knowledge no longer requires application to reality; knowledge is what gets passed on silently, without comment, from one text to another. Ideas are propagated and disseminated anonymously, they are repeated without attribution; they have literally become idées reçues: what matters is that they are there, to be repeated, echoed, and re-echoed uncritically.

The creation and reproduction of a particular vision on the Chinese language, especially on its writing system, has led us to the present status quo. Our analysis differs from previous ones in that it highlights the impact of this vision on Chinese language teaching and in that it focuses on the Spanish educational context, characterised, on the one hand, by a lack of tradition in Chinese Studies and a scarcity of reference materials and, on the other hand, by the deep reforms that are currently taking place at three different levels. Firstly, new courses in Chinese Studies have been set up in the last few years and an undergraduate programme in East Asian Studies is about to be launched for the first time in Spain. Secondly, university curricula are being homogenised under the European Convergence in Higher Education scheme (to be completed in 2010). Finally, a new policy to standardise language learning, teaching and assessment at all stages of education is being implemented all over the European Union. Although this policy was originally designed for European languages, the first attempts to apply it to non-European languages are now being made. We believe that this situation calls for an in-depth analysis of the knowledge to be transmitted and the pedagogical approaches to be used in the area of Chinese Studies, and in particular Chinese language teaching.

This article works from the basis of two main hypotheses. First, that most of the descriptions of the Chinese language are based on a series of myths that have evolved from an exotic vision which is either uninformed or based on certain vested interests, 
rather than descriptions based on well argued and founded academic research and study. The second hypothesis is the ambivalent view of the Chinese language which, on the one hand, has added to promoting an orientalist image and, on the other hand, has led to analysis and reforms of the language that have been strongly influenced by Western views and models.

The objectives of this article are three-fold: a) to identify the main myths and misconceptions surrounding the Chinese language and ascertain the context in which they were formulated, b) to show how these myths have been articulated in discourses and how they have permeated into Modern Chinese language teaching, c) to draw attention to how they have become such powerful and unchallenged discourses to the extent that reform initiatives of the Chinese language were influenced by Western linguistic models as a result of an orientalist view of their own language.

For our analysis, we will look into some of the first texts that helped building Western discourses on the Chinese language. We will illustrate how the image built by these discourses still persists in current teaching and reference materials, despite evidence which seriously questions their validity. In order to achieve our goals, we will take a discourse analysis approach inspired by Said's (1979), DeFrancis' (1984) and Shi-xu's (2005) works, mainly adopting deconstructing strategies through identifying, challenging and demystifying discourses partly derived from cultural imperialism. Breaking down the myths behind deeply entrenched suppositions concerning Chinese, we attempt to contribute to changing the typical image of Chinese, consciously or unconsciously perpetuated, also through formal language training. Our aim is not merely to repeat already formulated criticism to the formation and reproduction of knowledge about the Chinese language, such as that of DeFrancis (1984) or Tong (2007) but rather, on one hand, to add new source data material not included in previous analysis and, on the other hand, to highlight the fact that although some features of Chinese writing have already been pointed out by scholars for decades, they have not been sufficiently taken into account in the curricula nor have the existing discourses on Chinese language changed substantially.

\section{The orientalisation of the Chinese language: myths and misconceptions}

The publication of The Chinese Language: Fact and Fantasy by DeFrancis (1984) marks a change of direction in our understanding and description of Chinese in 
the Western academic world because of its critical, and to a certain degree revolutionary, approach. The distinguishing feature of this book is that it discredits a series of beliefs handed down across time practically unchallenged: the ideographic myth, the universality myth, the monosyllabic myth, the emulability myth, the indispensability myth and the successfulness myth. In this article we focus on the first three, adding a further myth of our own: the absence of grammar myth, especially relevant to modern Chinese language teaching.

\section{The ideographic myth}

Chinese has often been described as ideographic or pictographic, that is, consisting of symbols rather than letters which designate a concept, and a writing system which does not reflect pronunciation. These ideas spread throughout the Western world after the arrival of Christian missionaries in China during the sixteenth and seventeenth centuries -Matteo Ricci's works being the most influential ones- and also circulated among the Chinese themselves, as can be seen in the following explanation of Chinese characters given by a Chinese convert to Christianity who worked as an advisor to the missionaries (Mémoires 1776, 24, cited in DeFrancis 1984, 134):

[T] hey are composed of symbols and images, and that these symbols and images, not having any sound, can be read in all languages, and form a sort of intellectual painting, a metaphysical and ideal algebra, which conveys thoughts by analogy, by relation, by convention, and so on.

The Spanish missionary Martín de Rada expresses himself in similar terms in a letter dated 1575, from which we can gather that each concept is represented by a different character and so the language would need as many characters as there are concepts:

[T]he writing is the most barbarian and difficult to read that has ever been discovered because the letters are more like characters. They have a different letter for each word or thing so that even if one understood ten thousand letters, it would not be possible to read everything, and likewise among themselves he who can read most is [considered] the wisest.

Since then, this idea has been reiterated across the centuries without being much questioned, even within academic and sinological circles. 
Nowadays despite the fact that it is generally agreed that there is a phonetic component to Chinese written characters, there is still a tendency within the academic world to overstate the ideographic component of Chinese writing, by placing emphasis on the few existing pictographic and ideographic characters in the language and playing down the phonetic component or ignoring it altogether. For example, acclaimed sinologists such as Li and Thompson $(1982,77)$ refer to Chinese characters as a writing system which is 'semantically, rather than phonologically grounded' and hold that a Chinese character 'does not convey phonological information except in certain composite logographs where the pronunciation of the composite is similar to one of its component logographs.' Iljic $(2001,74)$, likewise, in his study on the origins of the suffix 们 (men), rather forthrightly states that Chinese 'is a language with a nonphonetic writing system.'

Another common misconception closely related to this last point is the use of the terms 'pictogram' and 'ideogram' as synonyms for Chinese characters, as illustrated in the following quote:

The Chinese language of high antiquity, which goes back to the first millennium

$\mathrm{BC}$, has remained accessible to educated speakers of Chinese by virtue of having been recorded in the form of characters, i.e. ideographs. (Hung and Pollard 1998, $365)$.

Most probably, this idea prevails in Spain as well, since it can be found in the few materials available to students in their mother tongue. For example, Marco and Lee $(1998,12)$ claim that '[i]t is true that characters or ideograms have undergone different modifications along the centuries (...).' Another prominent example is the following quote from the first Chinese grammar ever published in Spain, where the authors (both Chinese) affirm:

汉字 Hànzì, Chinese writing or Chinese characters, basically hieroglyphic, ideographic and not phonetic, constitutes the major obstacle in Chinese language learning both for foreigners and for the Chinese themselves. (Xu and Zhou 1997, 13)

Statements of this nature add further to what is a very biased and distorted view of written Chinese and, by analogy, of the Chinese language. In fact the ideograph issue has been the subject of debate for decades, with its supporters and detractors. Although there is still no consensus on this matter, this unworkable view remains the predominant 
one. By way of contrast, DeFrancis (1984, 133), Hannas (1997, 105), Qiu (2000, 22-3) and Unger $(2004,19)$ hold that written Chinese is phonetic rather than ideographic, as more than $90 \%$ of Chinese written characters are based on a picto-phonetic composition principle, while pictographic and ideographic characters taken as a whole only account for 3\%. In other words, almost all Chinese characters are comprised of both semantic and phonetic components which to one degree or another convey a vague idea about their meaning and pronunciation. A direct association between the semantic component and the meaning of the character accounts for only $1 \%$ of these cases, while the phonetic component of $25 \%$ of the picto-phonetic characters provides exact information on the pronunciation of these characters. If we include those cases in which the information is not accurate but approximate, then this figure rises to $66 \%$.

Referring more specifically to the teaching of the Chinese language, Xing (2006, 112-5) points out that although many scholars have acknowledged the fact that Chinese characters have phonetic components, they have been underestimated and have not been sufficiently incorporated into the teaching methods.

Although it is generally believed that the origins of written Chinese were most likely pictograms, as suggested by archaeological remains available to us today, this character formation principle soon proved to have its limitations and necessitated resorting to other more productive character formation principles. A historical view of the language reveals that an entirely pictographic or ideographic writing system is by no means practical and likely not even possible, not to mention having implications at a cognitive level that go beyond human abilities. It is for this reason that the use of terms such as 'ideogram', 'pictogram', 'ideographic writing' and 'pictographic writing', which reinforce the idea of concepts represented via characters rather than morphemes, is infelicitous. Rather, since Chinese writing is mainly constituted by characters consisting of a graphic symbol belonging to the morphemic level (semantic component) and another that expresses a syllable (phonetic component), we believe that other terms such as 'morphosyllabic writing', as proposed by DeFrancis $(1984,123)$ and Qiu $(2000$, 26) are better suited.

An explanation to the reproduction of the myth may be found in the fact that the existence of a purely pictographic language is an appealing idea for both the Chinese themselves, who created it coining the term biaoyi wenzi 'semantic writing', as well as for those in the Western world for whom the discovery of a pictograph-based language satisfied a need to find the original or primitive language. In other words, if this myth is 
still perpetuated today it is because it has become the prime exponent of Chinese culture allowing the Chinese people to mark out their own identity in terms of difference compared to the West, and in the West it is used to maintain the idea of strange and exotic, reinforcing orientalist views. Thus, apparently both sides have a vested interest in continuing to spread this myth. On the one hand, it is a contributing factor to the cultural pride and essentialist view of the Chinese people, which has made writing an instrument for political, social and cultural supremacy at a national level. Alternatively, from a Western perspective, it is a powerful element in arguments promoting exoticism that are used to construct an idea of impenetrability and make a clear distinction between us and the other.

\section{The universality myth}

The myth of the universal nature of written Chinese is very closely linked to the ideographic myth and basically revolves around three assumptions or beliefs:

- written Chinese is comprehensible at different stages throughout its history. In other words, today it is possible to read texts written 2,000 years ago;

- Chinese from different parts of the country can understand each other through the written form when their spoken languages are mutually unintelligible;

- Chinese characters are able to operate as a kind of universal means of communication because they have allowed the peoples of different countries and cultures, such as Japan, Korea, Vietnam and China, to communicate with each other.

Missionaries in the sixteenth century, inspired by Ricci's account of the Chinese language, claimed Chinese was a written language that was common throughout Asia, and because of this it could become a universal language for the rest of the world. Escalante states the following, in a report addressed to the archbishop of Seville in 1577:

And what is most praiseworthy is that although they speak different languages in the other provinces and are unable to understand each other any more than Basques and Valencians, in general they can understand each other through writing because a unique figure or character is used by everyone to signify any given noun. And even though they use different words when they speak, they can understand the same thing, because if they see the character for 'city' (which for some is Ieombi while for others it is Fu), they all understand that this 
means city. The same is the case for the other nouns and in this way the people of Japan, the Ryukyu Islands and the Cochin China Kingdom can communicate through writing when they cannot understand each other through speech.

Matteo Ricci, in his book De christiana expeditione apud Sinas ab Societate Iesu suscepta $(1615,27)$, insists on the international nature of written Chinese, since it was not only intelligible to the Chinese, but also to Japanese, Koreans and Taiwanese. European thinkers were quick to take up this idea as clearly illustrated in Proposition présentée au Roy, d'une escriture universelle, admirable pour ses effects, très-utile à tous les hommes de la terre (1627, cited in Eco 1994, 137), where the French thinker Jean Douet refers to the Chinese characters as an example of an international writing system.

Even though these views are correct to a certain extent in relation to classical Chinese, we consider these statements, which have formed the basis of the universality myth, as highly questionable when referring to modern Chinese because they are based on the following erroneous premises: Chinese characters are ideographs and the spoken language is independent of writing, that is, this writing system can be adapted to any other language. In addition, it is customary to assume, or even openly state, that the universal quality of written Chinese cannot be found in written languages based on an alphabet.

The first of the suppositions or beliefs surrounding the universality myth would have us believe that the Chinese language is static and has remained unchanged with the passing of time. This is by no means the case because, like all other languages, it has been subject to continual development. Moreover, this assumption implies that texts written in Classical Chinese, and even those written in early vernacular language, are easily accessible to the large majority of Chinese today, which is far from accurate, since they would need specialised language training to be able to understand them. Proof of this can be seen in modern editions of classical texts which are usually accompanied by a modern Chinese translation, or, at the very least, detailed notes to facilitate reading.

The second assumption is also open to question because, in effect, the different dialects and spoken languages of China share the same writing system in the same way that many European languages share the same alphabet. However, the fact that speakers of different sinitic languages and dialects may be able to understand each other through writing is not so much due to the fact that these spoken forms are written the same way, 
but rather to the fact that there is a tacit social consensus and adopted language norms that have maintained a homogenous written language, i.e. Modern Standard Chinese. So, if the Chinese are able to communicate through the writing, it is not because we are looking at a common written language that allows for language variations of Chinese, but because all speakers of the different languages and dialects resort to the same written standard which operates as a lingua franca in a role which is similar to that played by classical Chinese throughout the long history of the Chinese civilisation. In sum, if each linguistic variant spoken in China were to reproduce its phonological, morphological and syntactic peculiarities in written form, then written communication would not be so smooth as it apparently is today, since even recognising individual characters would not necessarily lead to understanding the text as a whole.

Another point which must be taken into consideration is that the graphic form is not homogenous across the whole territory. For instance, the written form used in Hong Kong consists of traditional characters as well as exclusive characters which represent the sounds in Cantonese; in Taiwan, the written language uses traditional characters as well as other exclusive characters to represent the sounds which are peculiar to minnanhua as well as Japanese words; and in mainland China, they use a simplified set of characters and, in contrast to the aforementioned territories, there are far fewer incidences of foreign loan words coming from English or Japanese.

The third claim, that Chinese characters can go beyond the national frontiers and serve as a means of communication between different peoples and cultures, is not false as such, but neither is it a feature which is exclusive to Chinese. This belief needs to be seen in a different context. DeFrancis (1984) rejects this myth by showing that languages based on alphabets fulfil their function far better than written Chinese, since people who speak different Indo-European languages could also understand each other through written language with far less formal training than would be the case for written Chinese. Thus, these two writing systems (Latin alphabet and Chinese characters) are equally capable of responding to the ideal of universality and, so this third assumption based on the myth of universality is somewhat overstated and, in any case, is not exclusive to Chinese. As can be seen in the case of English as a lingua franca today, as a means of international communication it is only within the reach of those who have learned it, i.e. it is universal only to a certain degree and actually quite elitist.

\section{The monosyllabic myth}


According to the monosyllabic myth, there is a one-to-one correspondence between word, character and syllable. This myth also derives from descriptions of the Chinese language by missionaries which in general were based on Classical Chinese a fact which should be borne in mind. Father Mateo Ricci (1615, 25-6), states that in Chinese, word, syllable, and written symbol are the same, that all words are monosyllabic, and that not even one disyllabic or polysyllabic word can be found.

This myth also derives from the confusion between language and writing and the fact that on paper characters have a graphic unity and are evenly set out, regardless of whether they are words or combine with other characters to form words. This graphic component has been a major influencing factor in perceiving Chinese as monosyllabic and has also been reinforced by the Chinese philology tradition, basically lexicographic, in which the character, not the word, is the object of study. This has meant a dearth of studies relating writing to the spoken language and has led to a poor and simplistic view of the Chinese language (DeFrancis 1984, 188).

Although it is true to say that each character represents a syllable and that in Classical Chinese there was a strong tendency towards monosyllabilism, there is no evidence to the effect that the spoken language has been monosyllabic at any given moment in time. In fact, Chinese language reformers at the beginning of the twentieth century went to great lengths to ensure that modern Chinese took on a written form which reflected the polysyllabic nature of the language spoken at that time. Although there is no unanimous opinion concerning statistics, as these depend to a great extent on the corpus and methodology used, various studies have shown that only $30 \%$ to $40 \%$ of Chinese characters are free morphemes (i.e. can constitute words by themselves) and that the rest are bound or semibound (DeFrancis 1984, 185).

\section{The absence of grammar myth}

This myth, which we have added to the list of myths highlighted up by DeFrancis and is directly related to the second part of this paper, consists of statements that the Chinese language is bereft of grammar or that its grammar is very simple. This is a myth which has also been promoted by both Chinese and Western scholars and which is often put forward as an argument to compensate for the difficulties posed by learning its morphosyllabic form of writing. 
In China, the discipline that traditionally dealt with philological studies was xiaоxue. This included writing, phonology and gloss; in other words, critical reading of ancient texts; as the name itself suggests, it was considered a minor discipline. Studies on Chinese grammar by Chinese grammarians did not begin until 1898, the year in which Ma Jianzhong published Mashi Wentong. This was a Chinese grammar based on Western grammars, ${ }^{1}$ a fact which has given rise to much criticism. However, the general consensus is that this work was an important milestone in Chinese linguistics and was a driving force behind research in Chinese grammar. According to Pan (1996, 107-10), before Mashi Wentong, Chinese philological studies had developed along autonomous lines, while all subsequent research has been directly influenced by Western approaches to linguistics, meaning that since then grammar has become a prime object of study.

In the West, the idea that Chinese does not have a grammar dates back to the early decades of the nineteenth century with the beginning of the first comparative linguistic studies and the search for a universal grammar. Taking Indo-European languages as a model, and in particular their distinctive grammatical characteristics, a classification of the languages of the world by type was drawn up, which is still generally accepted. According to this classification, made popular by von Humboldt, languages can be divided into three major groups: isolating or analytic languages (with Chinese as a prime example); agglutinative languages (such as Turkish); and inflecting languages (like the Indo-European languages). This classification is biased because it is based on morphology, which is a characteristic of Indo-European languages, and overlooks other aspects peculiar to languages outside the Indo-European group. Influenced by Darwin's theories, August Schleicher (1863, cited in Ramsey 1987, 4950) goes a step further when he states that languages were also subject to evolution, in that they all began with much simpler structures, as in the case of Chinese; some went through a period of agglutination; and the most highly evolved became inflecting languages. Mounin $(1970,188-9$, cited in Calvet 1981, 113) believes that IndoEuropean languages have reached an evolutionary peak, below which we have the less civilised languages.

So it can be seen that a given analytical model was imposed in the nineteenth century which worked from the basis that not all languages are equal and according to which inflecting languages are the model because they are considered to be richer and more developed. In contrast, isolating languages, like Chinese, are located at the other extreme of the evolutionary chain, i.e. labelled as inferior and underdeveloped. This 
belief has had important consequences for the image associated with the Chinese language as an instrument for reason and expression and translates as Chinese being perceived as a language which suffers from important deficiencies, seriously holding back the development of the Chinese people at a stylistic, philosophical and academic level. So here we have a classification of Chinese which is still commonly found, unquestioned from within academic circles and infused with ethno-centric and postcolonial ideology. As will be seen in the next section, this view also influenced Chinese reformers who attributed the backwardness of the country in relation to the West to their language, among other things.

The zero grammar myth comes from a very narrow definition of grammar based on applying a linguistic model that does not account for the linguistic diversity in the world. Along these lines, Gil $(2000,173)$ refers to linguistic Eurocentricity in the following terms:

$[C]$ ontemporary theories and frameworks do not provide the appropriate tools for a satisfactory description of such 'exotic' languages. In general, available theories are of European origin, reflecting the peculiar properties of the particular European languages familiar to their progenitors. Often, their application to languages spoken in other parts of the world is an exercise in Eurocentricity, involving the unwarranted imposition of categories and structures that are simply irrelevant.

Imposing foreign and inappropriate models on the Chinese language has resulted in paradoxical situations, such as descriptive Chinese grammars which do not include certain grammatical categories because they do not exist in European languages, or they are a rare occurrence. The immediate consequences of applying these kinds of models are apparent in the contents of grammars, which reveal that certain linguistic categories or phenomena in Chinese are completely misrepresented or distorted. As Shi-xu (2006, 385) puts it, 'when solely Western frameworks, with their inherent values and interests, are applied to the Chinese context, it is not hard to imagine the sort of conclusion that the research can lead to'.

An illustrative example of this is the treatment given to the grammatical category of measure words (or classifiers) in Chinese. Despite being a linguistic feature found in many languages in the world, measure words are a practically unknown category for Western linguists, and consequently are assigned a very minor role in studies on linguistic universals, as Lyons $(1977,460)$ points out in the following quote: 
Semanticists have devoted far less attention to classifiers than they have to determiners and quantifiers. The reason, no doubt, is that, although very many of the world's languages make use of classifiers, the more familiar IndoEuropean languages do not.

In fact, the lack of a corresponding category in European language grammars meant that Chinese linguists were at first undecided when it came to choosing the term that should be used to refer to measure words and the grammatical category that should be attributed to them. This explains why the first Chinese grammars either did not allow for the measure word category or they were not given the status of a different grammatical category (Rovira-Esteva 2002).

So, although arguments refuting the belief of zero grammar for Chinese as absurd and without basis gather inertia, this myth continues to be deeply entrenched, particularly in the area of teaching Chinese. A prominent example can be found in the proceedings of the $1^{\text {st }}$ National Conference for Chinese Language Teaching in Spain, where Lee and Liu (2008, 261-2) make the following description of Chinese grammar:

If we compare Chinese grammar with Spanish grammar we can say that

Chinese grammar is, in principle, less difficult because it lacks verbal endings.

However, modern Chinese grammar is based on English grammar (...) [sic].

Unfortunately, these kinds of statement are not as rare in Spain as one may think and are illustrative of the urgent need for breaking down rather uninformed discourses, since they still constitute elements that project a deformed and orientalist image of the Chinese language, which may in turn hinder Chinese language acquisition.

\section{Occidentalising the Chinese language}

The myths discussed so far, taken as a whole, have contributed to creating an essentialist, immutable and orientalist image of the Chinese language which to some extent has been used to differentiate and distance us from them. Furthermore, these myths have had a major impact on how the Chinese themselves see their own language as they have adopted this image for their own ends.

The late nineteenth century and early the twentieth century saw the beginning of a series of major reforms aimed at modernising China and bringing it in line with European powers and Japan. One of the first targets of this reform initiative was the language, including the written language which was considered too difficult and inferior 
to Western languages. From among the scholars at that time there were those who maintained that, '(...) from the point of view of learners and users, the Chinese script is inferior to the phonographic writings of Western languages and Japanese, and should be replaced by a phonetic system, or at least supplemented by one'. In addition it was also believed that, 'the difficulty of the writing system was largely responsible for the high rate of illiteracy in China, which in turn accounted for the country's weakness and ineptitude in the face of foreign powers' (Chen 1999, 166).

At the same time, many Chinese and non-Chinese intellectuals established a causality relationship between the apparent simplicity, or even absence, of grammar and the inability of Chinese to express abstract and scientific concepts. Wu (1969) stated that the weak point of the language and the Chinese way of thinking is precisely the lack of clarity and certainty, seen as characteristics of Western languages and thinking. Granet (1920, 150, cited in Needham and Harbsmeier 1998, 23) went as far as to say that: 'the Chinese language is inherently inappropriate for scientific analysis and precise scientific discourse.' The lack of consideration towards their own language and a generalised inferiority complex paved the way for some of the most preposterous statements that were totally bereft of any reasonable basis. For example: 'Germany is strong because its language contains many voiced sounds and China is weak because Mandarin lacks them (...)' (Li 1934, cited in Ramsey 1987, 7). This is not an isolated anecdotal comment and can only be explained in terms of the historical context in which it was made. As a result, the Chinese language became the target of harsh criticism by the reformers since it was seen as being responsible for social and political problems and generally responsible for China being so underdeveloped at that time; so the language became one of their main obsessions.

There was a lack of agreement among the reformers on how to begin modernising the country through the language, which was the focus of heated debates in academic circles and included some rather radical proposals. For example, Qian Xuantong in a letter addressed to Chen Duxiu, states, among other things: '(...) if you want to get rid of the average person's childish, uncivilized, obstinate way of thinking, then it is all the more essential that you first abolish the Chinese language (Qian 1918, cited in Ramsey 1987, 3). Qian Xuantong's proposed solution (1935, 141-6, cited in DeFrancis 1984, 243) ran along the lines of substituting Chinese for Esperanto or any other foreign language. 
Notwithstanding, the proposals which met with the greatest degree of acceptance were those which advocated the westernising of Chinese as the only way of compensating for its inherent shortcomings. Along these lines of reasoning $\mathrm{Fu}$ and Qian suggested that reforms should be based on the spoken language and, incorporate grammatical constructions from European languages in order to accommodate the need to convey complicated thoughts,' (Fu 1918; Qian 1918b, cited in Chen 1999, 80).

Thus, the reform of the Chinese language began at different levels. On the one hand, an attempt was made to bring written Chinese closer to the spoken language, substituting Classical Chinese for vernacular language. There were also those who wanted to go further and replace the morphosyllabic writing with an alphabetical writing system, which resulted in various systems for romanising and transcribing Chinese, although to date none of these have managed to replace of Chinese characters. On the other hand, the Chinese language was subject to a strong influence from Western languages which led to the so-called 'europeisation' of Chinese grammar.

Most scholars argue that this Western influence took shape at different linguistic levels: lexicon, grammar and orthography. As regards lexicon, this can be seen with the incorporation of a great number of neologisms, which either took the form of loan words which were adopted from the phonetics of the source language (as in the words tusi (土司) from the English 'toast'), or loan words which were translated semantically (as in the case of kao mianbao (烤面包), which literally means 'toasted bread') (Kubler 1985, 39).

As regards grammar, the most noteworthy innovations were in morphology, such as: nominalisation with the suffix xing (性), verbalisation with the suffix hua (化), graphically distinguishing the three forms of the third person singular $t a$ (他, 她 and 它), the use of the verb particle zhe (着) to indicate the continuous verb aspect, zai (在) to indicate the progressive aspect, and the grammatical distinction of the three structural particles de (的, 得 and 地). In addition, there was also an increase in the use of passive sentences, long and complex sentences and prepositions immediately after the verb. All of these changes attempted to transform Chinese into a clearer and more systematic language, taking Indo-European languages as the model to follow. 
Finally, as regards orthography, Western influence can be seen in three particular areas. First, a change in the direction in which writing was set out: writing now was horizontal beginning from left to right. Second, the introduction of Western punctuation criteria, a feature which Zhao Yuanren and Hu Shi (cited in Wang 2006, 95-6) believed would make Chinese more scientific, since historically Chinese was not usually punctuated. And, third, as mentioned earlier, different systems were created to romanise writing.

Although attempts at modernising the Chinese language were not limited to simply 'europeising' its grammar, Kubler $(1985,63)$ states the strong influence of foreign languages on attempts to reform the standard Chinese language in all the aforementioned aspects and concludes that, '[i]t is clear, then, that Europeanized grammar has become firmly entrenched as part and parcel of Modern Chinese grammar itself $^{2}$

The high degree of Western influence was possible, firstly, because vernacular language came to replace classical Chinese, and, secondly, due to the lack of standardisation of the new language, thus making the language more open to foreign influences. In addition, the proliferation of the press and the large number of translations of Western literature by writers who would later incorporate characteristics of Indo-European languages in their writings in Chinese, also played an important role in the 'europeisation' of Chinese. In short, Modern Chinese was the object of a deliberate application of a Western model by Chinese linguists themselves in an attempt to modernise the language, allow the country to develop and progress from being an underdeveloped country.

\section{Conclusions}

In this article we have identified a series of myths and misconceptions that form the basis of discourse on the Chinese language which are as deeply entrenched at a popular level as well as in academic discourse. We have chosen four of these myths on the basis of their impact and relevance to Chinese language teaching: the ideographic myth, the universality myth, the monosyllabic myth and the absence of grammar myth.

We have seen that the ideographic myth is based on the erroneous assumption that Chinese characters represent concepts with no reference to pronunciation. Although we need to bear in mind the pictographic origins of written Chinese and the importance 
of their semantic component as a principle for word formation, we must not forget the relevance of its phonetic components and the fact that written Chinese transmits meaning by means of sounds, however imperfect its system may be.

Universality is another pervasive myth based on overstating the ability of written Chinese to be used as a universal means of communication, since it overlooks the difficulties involved in learning it. In other words, it does not take into account that, firstly, those who are able to read texts dating from other eras have received specific training, and, secondly, the potential of written Chinese as a means of communication across the Chinese languages or different cultures requires prior training of a standard way of writing which is foreign to many. If this were not the case, neither Vietnam, Korean nor Japan would have felt the need to reform or even dispense with this morphosyllabic writing to adapt it to the characteristics and needs of their own language.

The monosyllabic myth originates from the confusion between, on the one hand, character and word, and, on the other, between language and writing. Given that there are serious studies which demonstrate that Chinese is not monosyllabic, we can only conclude that the belief that Chinese is a monosyllabic language is valid only in reference to written Classical Chinese.

Finally, the myth that Chinese is devoid of grammar is based on seeing Chinese as lacking grammar, for example, that Chinese does not have gender or number endings. Therefore the image that is given is that of a very simple language because it has no grammar and, at the same time a language that is unable to express certain meanings, hence the belief that Chinese is an inappropriate language for science. Whatever the case, Chinese is ranked as being inferior to European languages. As we have seen, this kind of discourse has not only surfaced in publications on Chinese by Western authors; it can also be heard from the Chinese themselves. We should not forget that in China the need to study and describe grammar was not an issue until contact was established with the West and Western linguistic theories and models began to be applied to Chinese with the rise of comparative linguistics and the search for linguistic universals.

What can be gathered from an analysis of a series of descriptive discourses on Chinese is ambivalence or views ranging from admiration to rejection, both inside and outside China. Obviously, discourse is not monolithic; it changes with the sociopolitical context at any given moment in time, or from person to person, and can be more or less explicit. The question that needs to be asked is why these myths have been 
in circulation and transmitted over such a long period of time, practically unchallenged and, although there are other discourses questioning these views, they have been marginalized or silenced, consciously or not, especially within Chinese language teaching. On the one hand, they have served Western interests to view the Chinese language in terms of exotism, regression and primitivism and, by analogy, the Chinese civilisation that has sheltered it. On the other hand, it has also been exploited by the Chinese themselves to promote the image of a refined, sublime and immutable culture whose writing is its main exponent as it entwines language and art and bears all their essential qualities.

We have also underlined how at a time of profound national crisis, Chinese intellectuals and politicians adopted the orientalist discourse on Chinese for their own purposes and, under Western influence, put into operation a series of language reforms (graphic representations grammar, etc.) in order to transform their language and bring it closer to the Western model, since it was generally believed that the language was the cause of all the country's ills and that only through the language would it be possible to modernise Chinese society at all levels.

The majority of the myths that we have discussed here correspond to metonymic descriptions of the Chinese language, that is, that a part (the most striking or that most distances it from the West) is used to describe a much more complex whole, a fact which generally speaking has contributed to projecting an orientalist and narrowminded view of the Chinese language. These metonymical projections are mainly derived from the application of Western models to analyse Chinese language and writing, out of awareness that these models are not necessarily universal and that their application is no more than the exertion of cultural imperialism.

We believe that the topics raised in this paper are especially relevant to the Spanish context since, on the one hand, we are experiencing an increase on graduate and postgraduate courses on Chinese Studies without the experience and background of other Western countries with a solid tradition in this field. On the other hand, university curricula are being unified and homogenised at a European level and, simultaneously, language learning, teaching and assessment are also being standardised under the "Common European Framework of Reference for Languages", which also affects Chinese.

In the light of these changes, it is all the more necessary that we learn from the past and avoid the perpetuation of statements that, taken out of context and repeated $a d$ 
nauseum, without the necessary clarifications, have built up an image of the Chinese language which is far removed from reality. At the same time, all the agents involved should seize the opportunity that this new context brings us to be more reflexive and critical in order to change the status quo and bring forth new approaches when producing and reproducing knowledge related to the Chinese language.

This article does not presume to be any more than a first step for future research in the area of Chinese linguistics which, from our point of view, has not yet been the target of postcolonial discourses. It is, therefore, the first stage of a research project which aims at analysing the influence exerted by orientalist discourse on contemporary studies on the Chinese language and specifically its impact on Chinese language teaching methodologies and materials. As scholars in an emerging field of studies, we have now the opportunity to make sure that, using Said's words, knowledge applies to reality and ideas are not re-echoed uncritically.

\section{Acknowledgements}

This study has received the backing of the Universidad Autónoma de Barcelona and was carried out within the context of the project 'Interculturalidad en Asia Oriental (INTER-ASIA)' (2005-2008) sponsored by the Spanish Ministry for Education and Science under the Plan Nacional de I+D+I (Ref. HUM 2005-08151). This paper has also benefited from suggestions made by the Editor and two anonymous referees as well as our colleagues from Inter-Asia Research Group.

\section{Notes}

1. Peyraube (2001) concludes in his study of the sources of this Chinese grammar that it was mainly influenced by Antoine Arnauld and Claude Lancelot's Grammaire de Port Royal (1660). 2. Even though this is the most widespread view, Peyraube (2000) claims that the influence of Western languages on Chinese succeeded in the area of vocabulary, but it was quite limited on grammar.

\section{References}

Calvet, Louis-Jean. 1981. Lingüística y colonialismo. Madrid: Júcar. 
Chen, Ping. 1999. Modern Chinese. History and Sociolinguistics. Cambridge: Cambridge University Press.

DeFrancis, John. 1984. The Chinese Language. Fact and Fantasy. Honolulu: University of Hawai Press.

Eco, Umberto. 1994. La búsqueda de la lengua perfecta. Barcelona: Crítica.

Escalante, Bernardino de. 1577. Discurso de la navegacion que los Portugueses hazen à los Reinos y Provincias del Oriente, y de la noticia que se tiene de las grandezas del Reino de la China. Escola d'Estudis d'Àsia Oriental, Universitat Pompeu Fabra. http://www.upf.edu/asia/projectes/che/s16/escal.pdf (accessed September $23,2008)$.

Gil, David. 2000. Syntactic Categories, Cross-Linguistic Variation and Universal Grammar. In Approaches to the Typology of Word Classes, ed. Petra Maria Vogel and Bernard Comrie, 173-216. Berlin and New York: De Gruyter.

Hannas, William C. 1997. Asia's Orthographic dilemma. Honolulu: University of Hawaii Press.

Hung, Eva and David Pollard. 1998. Chinese tradition. In Routledge Encyclopedia of Translation Studies, ed. Mona Baker, 365-74. London and New York: Routledge.

Iljic, Robert. 2001. The Origin of the Suffix -men 們 in Chinese. Bulletin of SOAS 64, no. 1: 74-97.

Kubler, Cornelius C. 1985. Europeanized grammar in Ba Jin's novel Jia. Journal of the Chinese Language Teachers Association 20, no. 1: 39-66.

Li, Charles N., and Thompson Sandra A. 1982. The Gulf Between Spoken and Wirtten Language: A Case Study in Chinese. In Spoken and Written Language: Exploring Orality and Literacy, ed. Deborah Tannes, 77-88. Norwood, New Jersey: Ablex.

Lee Tsang, Sai Kin, and Liu Ya-chi. 2008. ¿Existe una metodología ideal? In La enseñanza de la lengua china como lengua extranjera en España, ed. M. ${ }^{\mathrm{a}}$ Ángeles Iglesias et al., 243-268. Valladolid, Ayuntamiento de Valladolid.

Lyons, John. 1977. Semantics. Vol. 2. Cambridge: Cambridge University Press.

Marco, Consuelo, and Wang-Tang Lee. 1998. Gramática de la lengua china. Taipei: Bianyiguan. 
Needham, Joseph, and Christoph Harbsmeier. 1998. Science and Civilization in China. Vol. VII: 1, Language and Logic. Cambridge: Cambridge University Press.

Pan, Wenguo. 1996. Bijiao Han-Yingyu yufa yanjiu shi de qishi (xu). Yuyan jiaoxue yu yапjiu 3: 107-22.

Peyraube, Alain. 2000. Westernization of Chinese grammar in the 20th century: myth or reality? Journal of Chinese Linguistics 28, no. 1: 1-25.

Peyraube, Alain. 2001. Some Reflections on the Sources of the Mashi Wentong. In New Terms for the New Ideas. Western Knowledge and Lexical Change in Late Imperial China, ed. Michael Lackner, Iwo Amelung and Joachim Kurtz, 341356. Leiden et al: Koninklijke Brill.

Qiu, Xigui. 2000. Chinese Writing. Berkeley: The Society for the Study of Early China.

Rada, Martín de. 1575. Relaçion verdadera delascosas del reyno de Taibin por otro nombre china y del viaje que ael hizo el muy Reverendo padre fray martin de Rada provinçial que fue delaorden delglorioso Doctor dela yglesia San Agustin. quelo vio yanduvo en la provinçia de Hocquien año de 1575 hecha porelmesmo. Escola d'Estudis d'Àsia Oriental, Universitat Pompeu Fabra. http://www.upf.edu/asia/projectes/che/s16/ radapar.pdf (accessed September 23, 2008).

Ramsey, Robert S. 1987. The Languages of China. New Jersey: Princeton University Press.

Ricci, Matteo. 1616. De christiana expeditione apud Sinas ab Societate Iesu suscepta. Lyon: Horatio Cardon.

Rovira-Esteva, Sara. 2002. El paper dels mesuradors xinesos en la pragmàtica del text. $\mathrm{PhD}$ diss., Universitat Autònoma de Barcelona.

Said, Edward. 1979. Orientalism. Western Conceptions of the Orient. New York: Vintage Books.

Shi-xu. 2005. A Cultural Approach to Discourse. Houndmills and New York: Palgrave Macmillan.

Tong, Q. S. 2008. Between knowledge and 'plagiarism', or, how the Chinese language was studied in the West. Language Sciences 30: 499-511.

Unger, James Marshall. 2004. Ideogram: Chinese Characters and the Myth of Disembodied Meaning. Honolulu: University of Hawaii Press. 
Wang, Hui. 2006. Discursive Community and the Genealogy of Scientific Categories. In Everyday Modernity, eds. Madelaine Yue Dong and Joshua Goldstein, 80117. Seattle and London: University of Washington Press.

Wu, Joseph S. 1969. Chinese Language and Chinese Thought. Philosophy East and West 19, no. 4: 423-34.

Xing, Janet Zhiqun. 2006. Teaching and Learning Chinese as a Foreign Language. A Pedagogical Grammar. Hong Kong: Hong Kong University Press.

$\mathrm{Xu}$, Zenghui, and Minkang Zhou. 1997. Gramática china. Bellaterra: Servei de Publicacions de la Universitat Autònoma de Barcelona.

\section{Bionotes}

Helena Casas-Tost, B.A. in Translation and Interpreting from the Autonomous University of Barcelona, M.A. in Chinese Studies from SOAS (University of London) and M.A. in International Relations from Beijing University. She teaches Chinese and Translation from Chinese into Spanish in the Department of Translation and Interpreting at the Autonomous University of Barcelona. She is also a freelance translator from Chinese and is currently writing her Ph.D. thesis on the translation of onomatopoeic words from Chinese into Spanish. Her research interests include translation studies, Chinese pedagogy and contrastive linguistics. She has published a number of papers on Chinese linguistics, Teaching Chinese as a foreign language, and Chinese-Spanish/Catalan translation. Email address: hcasastost@gmail.com.

Sara Rovira-Esteva, B.A. in Translation and Interpreting, Ph.D. in Translation Studies (Autonomous University of Barcelona). She teaches Mandarin Chinese, translation from Chinese into Spanish and Chinese culture at the Faculty of Translation and Interpretation (Autonomous University of Barcelona). She has worked as a professional translator translating mainly Chinese films and contemporary Chinese literature. Her research interests include translation studies, cultural transfer, Chinese pedagogy and contrastive linguistics. She has published a number of papers on ChineseSpanish/Catalan translation, Chinese linguistics and Teaching Chinese as a foreign language. Email address: Sara.Rovira@uab.cat. 